\title{
Nanofluid Flow over a Rotating Disk with Prescribed Heat Flux
}

\author{
Julie Andrews* and S P Anjali Devi†
}

\begin{abstract}
An analysis is carried out to study the problem of the steady flow and heat transfer over a rotating disk with a prescribed heat flux in nanofluid. Nanofluid considered is Copper $(\mathrm{Cu})$ with water as the base fluid. The governing partial differential equations are transformed into a set of nonlinear ordinary differential equations using similarity transformation, which are then solved using the Nachtsheim-Swigert Shooting iteration technique along with the fourth order Runga Kutta method. The features of the flow and heat transfer characteristics are analyzed and discussed. The radial velocity, tangential velocity and the axial velocity for copper-water nanofluid are calculated and are represented graphically. Numerical results for dimensionless temperature, the radial skin friction coefficient and the tangential skin friction coefficient of the nanofluid flows are obtained and computations are carried out for the various values of Prandtl number. It is found that for the prescribed heat flux case (PHF case), the effect of Prandtl number is to reduce the temperature as it increases for copper-water nanofluid.
\end{abstract}

Keywords: Nanofluid, rotating disk, prescribed heat flux, Laminar and axially symmetric flow.

\footnotetext{
Department of Mathematics, Mercy College, Palakkad-6, India; srjulia_cmc@yahoo.com.

† Department of Applied Mathematics, Bharathiar University, Coimbatore-46, India.
}

Received: July 2012, Reviewed. Aug. 2012 


\section{Introduction}

Research topic of nanofluids has been receiving increased attention worldwide. Many studies on nanofluids are being conducted by talented and studious thermal scientists and engineers all over the world and they have made scientific breakthrough not only in discovering unexpected thermal properties of nanofluids, but also in proposing new mechanisms behind the enhanced thermal properties of nanofluids and thus identifying unusual opportunities to develop them as next generation coolants for computers and safe coolants for nuclear reactors.

The flow dynamics due to a rotating disk is a popular area of research which has its origin long back. The problem of flow over a rotating disk is one of the classical problems of fluid mechanics that has both theoretical and practical values. The importance of heat transfer from a rotating body can be ascertained in cases of various types of machinery, for example computer disk drives (see Herrero et al. [1]) and gas turbine rotors (see Owen and Rogers [2]). Many have studied and reported results on disk-shaped bodies with or without heat transfer considering various flow conditions as they encountered in many industrial, geothermal, geophysical, technological and engineering applications of which a few are rotating heat exchangers, rotating disk reactors for bio-fuels production, computer disk drives, gas or marine turbine.

Rotating disk fluid flow problems have a long history back, with Von Karman [3] originally describing similarity transformations that enable the Navier-Stokes equations for an isothermal impermeable rotating disk to be reduced to a system of coupled ordinary differential equations. Later many comprehensive studies have been carried out on rotating disk flow by efficient researchers. Millsaps and Pohlhausen [4] was the first to consider the problem of heat transfer from a rotating disk maintained at a constant temperature for a number of Prandtl numbers in the steady state. In the case of gases, the effects of compressibility were examined by Ostrach and Thornton [5]. Till today, there have been many authors who have studied the heat transfer in the vicinity of a rotating disk for different thermal conditions. Sparrow and Gregg [6] studied the steady-state heat transfer from a rotating disk maintained at a 78 
constant temperature to fluids at arbitrary Prandtl numbers. The rotationally symmetric flow of a viscous fluid in the presence of an infinite rotating disk has been considered by Rogers and Lance [7]. It was Richardson and Saunders [8] who presented the flow and heat transfer associated with a rotating disk. The heat transfer from a rotating disk maintained at a constant temperature for large and small values of the Prandtl number was studied by Riley [9]. Rotationally symmetric flow above an infinite rotating disk was discussed by Bodonyi [10].

Due to the rapid development of modern technology, the recent microelectromechanical systems (MEMS) generate an enormous amount of heat, which disturbs the normal performance of the devices and reduces reliability. Therefore, an efficient cooling system is one of the most inevitable necessity in designing MEMS components [11], considerable research and development on MEMS cooling performance and improvements in cooling capabilities have been performed in the recent years. However a large number of these researches have been lacking because conventional fluids such as water, engine oil and ethylene glycol are normally used as heat transfer fluids in many industrial processes, including power generation, chemical processes, heating or cooling processes and microelectronics, which have poor heat transfer properties. The poor heat transfer properties of these ordinary cooling fluids compared to the most solids are a primary obstacle to the high compactness and effectiveness of heat exchangers. The essential initiative is to seek the solid particles having thermal conductivities several hundreds of times higher than those of conventional fluids. Therefore industrial cooling devices using nanofluids as coolants are increasingly important in current and future heat removal applications. An innovative idea is to suspend solid particles in the fluid to improve the thermal conductivity of a fluid.

Nanofluids are produced by dispersing the nanometer-scale solid particles into base liquids with low thermal conductivity such as water, ethylene glycol (EG), oils, etc. The term "nanofluid" was first introduced by Choi [12] to describe this new class of fluids. The materials with sizes of nanometers possess unique physical and chemical properties [13]. This fact has attracted many 
researchers such as Abu-Nada and Oztop [14], Tiwari and Das [15] and Maïga et al. [16-17] to investigate the heat transfer characteristics in nanofluids and they found that the presence of the nanoparticles in the fluids increases appreciably the effective thermal conductivity of the fluid and consequently enhances the heat transfer characteristics.

To the best of the knowledge of the authors, no other numerical study on the flow and heat transfer characteristics due to a rotating disk with prescribed heat flux (PHF Case) for copper-water nanofluid has been reported so far. The aim of the present paper is to study the flow and heat transfer characteristics due to a rotating disk with prescribed heat flux (PHF Case) immersed in a waterbased nanofluid containing nanoparticles of $\mathrm{Cu}$. The numerical solutions of the problem are obtained using fourth order RungeKutta based shooting method with the utilization of NachtsheimSwigert iteration scheme for satisfaction of asymptotic boundary conditions and are shown by means of graphs. The effects of the Prandtl number on copper-water nanofluid on the velocity and the temperature in the regime are depicted graphically and analyzed in detail. The effects of the parameter Pr on steady flow and heat transfer are presented and discussed. To determine the $k_{\text {eff }}$ of the nanofluid, the model given by Patel [18] has been used with appropriate value of ' $c$ ', which has been calculated by matching the experimental results. Since no other model takes care of the temperature dependence of $k_{\text {eff }}$ of the nanofluid, this model has been considered as the best option. The viscosity of nanofluid has been calculated using Brinkman model [19].

\section{Formulation of the Problem}

The steady, laminar, axially symmetric, incompressible flow of viscous nano fluid with heat transfer due to a rotating disk has been considered. The fluid is assumed to be to be Newtonian. Assume that the fluid is infinite in extent in the positive $\mathrm{z}$ direction. Let $(r, \phi, z)$ be the set of cylindrical polar coordinates and let the disk rotate with constant angular velocity $\Omega$ which is placed at $\mathrm{z}=$ 0 . The components of the flow velocity are $(\mathrm{u}, \mathrm{v}, \mathrm{w})$ in the directions of increasing $(\mathrm{r}, \boldsymbol{\phi}, \mathrm{z})$ respectively. The surface of the rotating disk is maintained at a uniform temperature $\mathrm{T}_{\mathrm{w}}$. Far away 80 
from the surface, the free stream is kept at a constant temperature $\mathrm{T}_{\infty}$ and at a constant pressure $\mathrm{p}_{\infty}$. The fluid properties are assumed to be constant in a limited temperature range. Under the above assumptions, the governing equations for the continuity, momentum and energy in laminar incompressible boundary layer flow in a nanofluid can be written as

$$
\begin{gathered}
\frac{\partial u}{\partial r}+\frac{u}{r}+\frac{\partial w}{\partial z}=0 \\
u \frac{\partial u}{\partial r}-\frac{v^{2}}{r}+w \frac{\partial u}{\partial z}+\frac{1}{\rho_{n f}} \frac{\partial p}{\partial r}=v_{n f}\left(\frac{\partial^{2} u}{\partial r^{2}}+\frac{1}{r} \frac{\partial u}{\partial r}-\frac{u}{r^{2}}+\frac{\partial^{2} u}{\partial z^{2}}\right) \\
u \frac{\partial v}{\partial r}+\frac{u v}{r}+w \frac{\partial v}{\partial z}=v_{n f}\left(\frac{\partial^{2} v}{\partial r^{2}}+\frac{1}{r} \frac{\partial v}{\partial r}-\frac{v}{r^{2}}+\frac{\partial^{2} v}{\partial z^{2}}\right) \\
u \frac{\partial w}{\partial r}+w \frac{\partial w}{\partial z}+\frac{1}{\rho_{n f}} \frac{\partial p}{\partial z}=v_{n f}\left(\frac{\partial^{2} w}{\partial r^{2}}+\frac{1}{r} \frac{\partial w}{\partial r}+\frac{\partial^{2} w}{\partial z^{2}}\right) \\
u \frac{\partial T}{\partial r}+w \frac{\partial T}{\partial z}=\alpha_{n f}\left(\frac{\partial^{2} T}{\partial r^{2}}+\frac{1}{r} \frac{\partial T}{\partial r}+\frac{\partial^{2} T}{\partial z^{2}}\right)
\end{gathered}
$$

The boundary conditions for this problem are given by

$$
\begin{aligned}
& u=0, \quad v=\Omega r, w=0, q_{w}=-k_{n f}\left(\frac{\partial T}{\partial z}\right) \quad \text { at } \quad z=0 \\
& u \rightarrow 0, v \rightarrow 0, \quad T \rightarrow T_{\infty}, p \rightarrow p_{\infty} \quad \text { as } z \rightarrow \infty
\end{aligned}
$$

where $T$ is the temperature of the nanofluid, $T_{\infty}$ is the temperature of the ambient nanofluid, $\mathrm{p}$ is the pressure of the nanofluid, $\mathrm{p}_{\infty}$ is the pressure of the ambient nanofluid, $a_{n f}$ is the thermal diffusivity of the nanofluid and $k_{n f}$ is the thermal conductivity, $v_{n f}$ is the kinematic viscosity, $\rho_{n f}$ is the density and $\mu_{n f}$ is the dynamic viscosity of the nanofluid respectively. 


\section{Copper water nanofluid}

The viscosity, heat capacity, density and thermal conductivity of the nanofluids depends on the volume fraction $\boldsymbol{\phi}$ of the nanoparticles used. The effective density of the nanofluid is given by

$$
\rho_{n f}=(1-\phi) \rho_{f}+\phi \rho_{s}
$$

and the specific heat capacity of the nanofluid is given by

$$
\left.\left(c_{p}\right)_{n f}=(1-\phi)\left(c_{p}\right) f^{+\phi\left(c_{p}\right)}\right)_{s}
$$

where $\rho_{f}$ and $\rho_{s}$ are the densities, $\left(c_{p}\right)_{f}$ and $\left(c_{p}\right)_{s}$ are specific heat capacities of the base fluid and solid particle respectively. Brinkman's [19] equation is used to find out the dynamic viscosity:

$$
\mu_{n f}=\frac{\mu_{f}}{(1-\phi)^{25}}
$$

where $\mu_{f}$ is the dynamic viscosity of the base fluid whose value is given by 0.001002 and $\phi$ is the solid volume fraction. The independent values of thermal properties of all the particles used are given in Table 1.

Patel et al. model [18] is used to determine the effective thermal conductivity $\mathrm{k}_{\mathrm{nf}}$ (which is denoted also as $\mathrm{k}_{\mathrm{eff}}$ ) of the copper-water nanofluid. For the case of copper-water nanofluid, thermal conductivity $\mathrm{k}_{\text {eff }}$ of the two component entity of spherical particle suspension, is given by

$$
\frac{k_{e f f}}{k_{f}}=1+\frac{k_{p} A_{p}}{k_{f} A_{f}}+\frac{c k_{p} P e A_{p}}{k_{f} A_{f}}
$$

where 


$$
\begin{aligned}
& \frac{A_{p}}{A_{f}}=\frac{d_{f} \phi}{d_{p}(1-\phi)} \\
& P e=\frac{u_{p} d_{p}}{\alpha_{f}}
\end{aligned}
$$

where $u_{p}$ is the Brownian motion velocity of the particle which is given by

$$
u=\frac{2 \pi k}{\pi \mu_{f} d_{p}^{2}}
$$

where $k_{b}$ is the Boltzmann constant $\left(\mathrm{k}_{\mathrm{b}}=1.3806 \times 10^{-24} \mathrm{~J} / \mathrm{K}\right)$ and $\mathrm{T}$ is the temperature. Here we take $A_{p}$ and $A_{f}$ are heat transfer areas of the paricle and the fluid respectively. $d_{p}$ represents the particle diameter and $d_{f}$ is the molecular size of the liquid, (i.e. the liquid particle size is taken as the molecular size of the liquid) is 2Angstroms $\left(2 \mathrm{~A}^{\circ}\right)$ for water. Here $a_{f}$ is the thermal diffusivity of the fluid. Thermal conductivities of the paricle and the fluid are denoted by $k_{p}$ and $k_{f}$ respectively. The value of constant ' $c$ ' as taken from the experimental data available for copper-water nanofluid is 36000 . The calculation of the effective thermal conductivity can be done using equation (10).

Table 1. Physical properties of base fluid water, copper, alumina at $20^{\circ} \mathrm{C}(293 \mathrm{~K})$

\begin{tabular}{|c|c|c|c|}
\hline & $\begin{array}{c}\rho \\
\left(\mathrm{Kg} / \mathrm{m}^{3}\right)\end{array}$ & $\begin{array}{c}\mathrm{c}_{\mathrm{p}} \\
(\mathrm{J} / \mathrm{Kg} . \mathrm{K})\end{array}$ & $\begin{array}{c}\mathrm{k} \\
(\mathrm{W} / \mathrm{m} . \mathrm{K})\end{array}$ \\
\hline \hline Water & 1000.52 & 4181.8 & 0.597 \\
\hline \hline Copper & 8954 & 383.1 & 386 \\
\hline
\end{tabular}




\section{Solution of the Problem}

To obtain the solutions of the governing equations, following von Karman, a dimensionless normal distance from the disk, $\eta=z\left(\Omega / u_{n f}\right)$ is introduced along with the following representations for the radial, tangential and axial velocities, pressure and temperature distributions:

$$
\begin{aligned}
& u=\Omega \operatorname{rf}(\eta), \quad v=\Omega r g(\eta), w=\left(\Omega v_{n f}\right)^{1 / 2} h(\eta) \\
& p-p_{\infty}=-\mu_{n f} \Omega p(\eta) \quad \text { and } T-T_{\infty}=\frac{q_{w}}{k_{n f}}\left(\frac{v_{n f}}{\Omega}\right)^{1 / 2} \theta(\eta)
\end{aligned}
$$

where $\mathrm{f}, \mathrm{g}, \mathrm{h}, \mathrm{p}$ and $\theta$ are dimensionless functions in terms of vertical co-ordinate $\eta$. Substituting equation (14) in equations (1-5) gives the following nonlinear ordinary differential equations,

$$
\begin{gathered}
2 f+h^{\prime}=0 \\
f^{\prime \prime}-h f^{\prime}-f^{2}+g^{2}=0 \\
g^{\prime \prime}-h g^{\prime}-2 f g=0 \\
h^{\prime \prime}-h h^{\prime}+p^{\prime}=0 \\
\frac{\theta^{\prime \prime}}{(\mathrm{Pr})_{n f}}-\mathrm{h} \theta=0
\end{gathered}
$$

where

$(\operatorname{Pr})_{n f}=\frac{\mu_{n f}\left(\mathrm{C}_{\mathrm{p}}\right)_{\mathrm{nf}}}{\mathrm{k}_{\mathrm{nf}}}$ is the Prandtl number of the nanofluid.

The transformed boundary conditions are given as

$$
\begin{aligned}
& f(\eta)=0, \quad g(\eta)=1, \quad h(\eta)=0, \quad \theta^{\prime}(\eta)=-1 \quad \text { at } \eta=0 \\
& f(\eta) \rightarrow 0, g(\eta) \rightarrow 0, p(\eta) \rightarrow 0, \theta(\eta) \rightarrow 0 \quad \text { as } \eta \rightarrow \infty
\end{aligned}
$$


Equation (18) can be used to solve for the pressure distribution if required. The boundary conditions given by equation (20) imply that the radial $(\mathrm{f})$, the tangential $(\mathrm{g})$ components of velocity and temperature vanish sufficiently far away from the disk, whereas the axial velocity component (h) is anticipated to approach a yet unknown asymptotic limit for sufficiently large $\eta$-values.

\section{Numerical Analysis}

In Prescribed Heat Flux case, equations (15), (16), (17) and (19) are solved numerically subject to (20) using Fourth-Order RungeKutta shooting method using Nachtsheim-Swigert scheme for the satisfaction of asymptotic boundary conditions. To initiate the shooting process, we have to make an initial guess judiciously for the values of $\boldsymbol{f}^{\prime}(\mathbf{0}), \boldsymbol{g}^{\prime}(\mathbf{0})$ and $\boldsymbol{\theta}^{\prime}(\mathbf{0})$. For different values of $(\mathrm{Pr})_{\mathrm{nf}}$, the different initial guesses were made taking into account of the convergence. Numerical results are obtained for several values of the physical parameter $(\mathrm{Pr})_{\mathrm{nf}}$.

\section{Skin Friction}

The radial skin-friction and tangential skin-friction coefficients are given by the Newtonian formulae

$$
\begin{gathered}
\tau_{t}=\left[\mu_{n f}\left(\frac{\partial v}{\partial z}+\frac{1}{r} \frac{\partial w}{\partial \phi}\right)\right]_{z=0}=\mu_{n f} g^{\prime} \Omega(\mathrm{Re})^{1 / 2} \\
\tau_{r}=\left[\mu_{n f}\left(\frac{\partial u}{\partial z}+\frac{\partial w}{\partial r}\right)\right]_{z=0}=\mu_{n f} f^{\prime} \Omega(\operatorname{Re})^{1 / 2}
\end{gathered}
$$

Hence the tangential and radial skin-frictions for prescribed heat flux case are respectively given by

$$
\begin{aligned}
& (\mathrm{Re})^{1 / 2} C_{f_{t}}=g^{\prime}(0), \\
& (\mathrm{Re})^{1 / 2} C_{f_{r}}=f^{\prime}(0),
\end{aligned}
$$

where $\operatorname{Re}=\left(\Omega r^{2} / v_{n f}\right)$ is the local rotational Reynolds number. 


\section{Results and Discussion}

Numerical solutions of steady, laminar, convective flow of a viscous, nano fluid over a rotating disk are obtained. In order to get a clear insight of the physical problem, the radial velocity $f(\eta)$, the tangential velocity $g(\eta)$, the axial velocity $h(\eta)$ and the temperature $\theta(\eta)$ have been obtained by assigning numerical values to the physical parameters encountered in the problem. Further, the numerical values for radial and tangential skin friction coefficients and wall temperature are also obtained which are presented through tables. Instead of $(\mathrm{Pr})_{\mathrm{nf}}$, for the ease of representation in graphs, the notation Pr is made use of throughout the figures.

Results are identical to that of Anjali Devi and Uma [21] for the case of Prescribed Heat Flux case in the absence of magnetic parameter, radiation parameter, suction parameter and heat generation/absorption parameter which can be seen clearly through Table 2.

Table 2: Comparison of the results of $\theta(0), f^{\prime}(0)$ and $-g^{\prime}(0)$ when $\operatorname{Pr}=7.02(\mathrm{PHF}$ Case)

\begin{tabular}{|c|c|c|c|c|}
\hline & $\operatorname{Pr}$ & $\theta(0)$ & $\mathrm{f}^{\prime}(0)$ & $-\mathrm{g}^{\prime}(0)$ \\
\hline $\begin{array}{c}\text { Author's } \\
\text { Result }\end{array}$ & 7.02 & 1.017305 & 0.5102326 & 0.6159220 \\
\hline $\begin{array}{c}\text { Uma and } \\
\text { Anjali } \\
\text { Devi(2011) }\end{array}$ & 7.02 & 1.017310 & 0.5102326 & 0.6159220 \\
\hline
\end{tabular}

Table 3: (PHF for copper water nanofluid) Variation of f' $(0),-$ g' $(0)$ and $\theta(0)$ for different values of $\mathrm{Pr}$

\begin{tabular}{|c|c|c|c|}
\hline $\operatorname{Pr}$ & $\theta(0)$ & $\mathrm{f}^{\prime}(0)$ & $-\mathrm{g}^{\prime}(0)$ \\
\hline 2.37 & 1.632460 & 0.5102326 & 0.6159220 \\
3.75 & 1.326638 & 0.5102326 & 0.6159220 \\
6.06 & 1.081013 & 0.5102326 & 0.6159220 \\
7.02 & 1.017305 & 0.5102326 & 0.6159220 \\
\hline
\end{tabular}




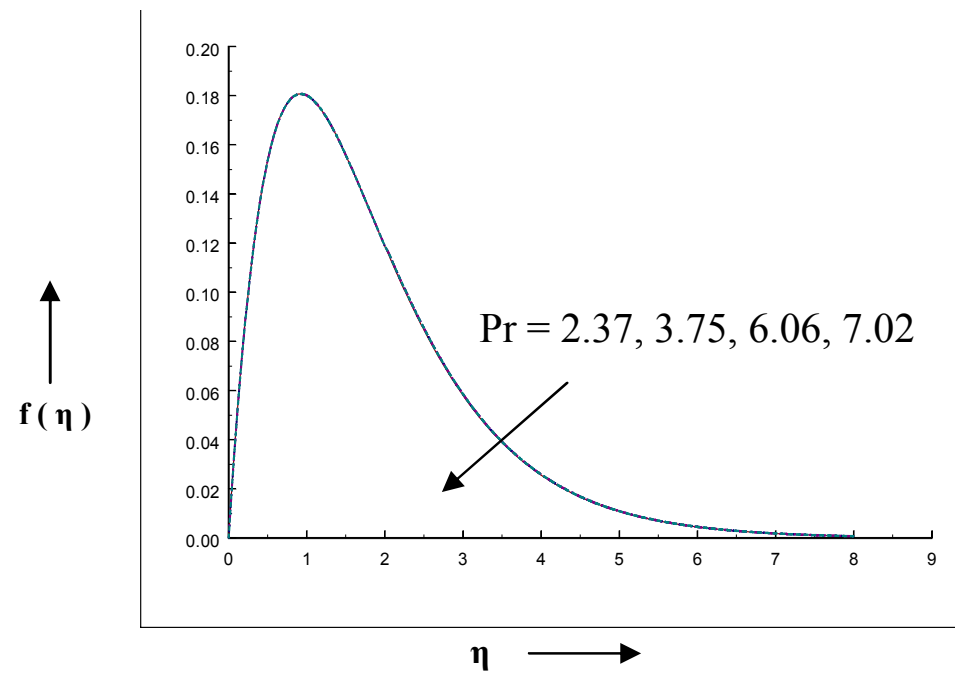

Fig.1 Effect of Pr on radial velocity for copper-water nanofluid

Fig. 1 to Fig. 3 represent the radial velocity $f(\eta)$, tangential velocity $g(\eta)$ and the axial velocity $h(\eta)$ in the boundary layer of copperwater nanofluid for various values of Pr. It is observed that there is little effect on different Pr values on radial velocity $f(\eta)$, tangential velocity $g(\eta)$ and the axial velocity $h(\eta)$. The influence of Prandtl number over the temperature for the Prescribed Heat Flux Case are depicted in Fig.4.The dimensionless temperature of the fluid decreases with increase of Prandtl number which is elucidated through Fig.4 for copper-water nanofluid.

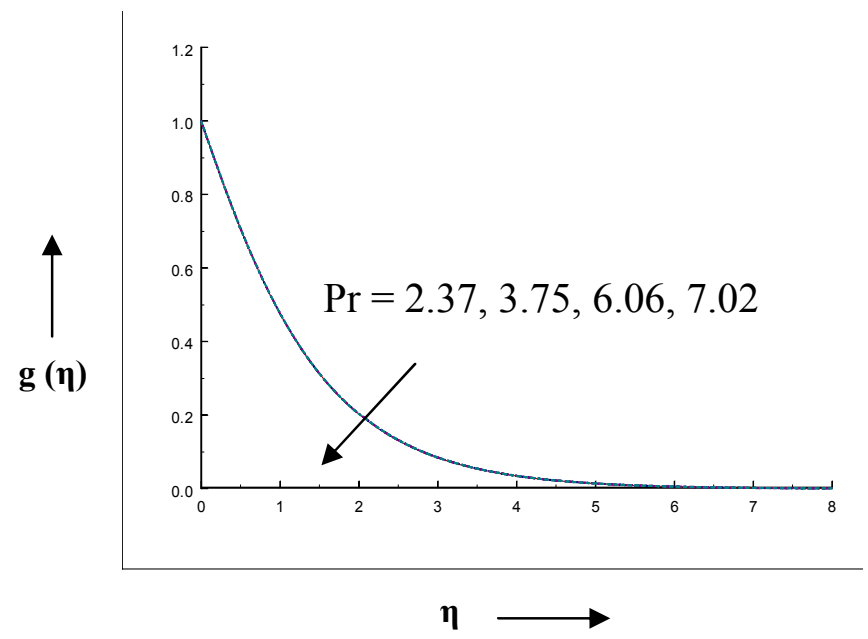

Fig. 2 Effect of Pr on tangential velocity for copper-water nanofluid 


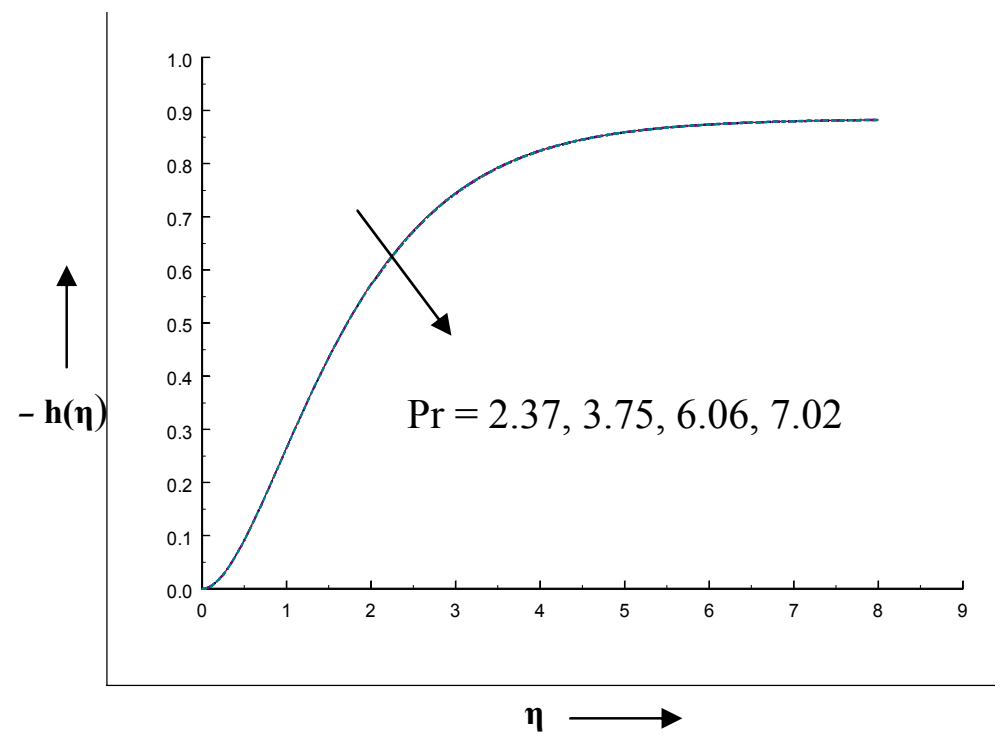

Fig. 3 Axial velocity for different Pr for copper-water nanofluid

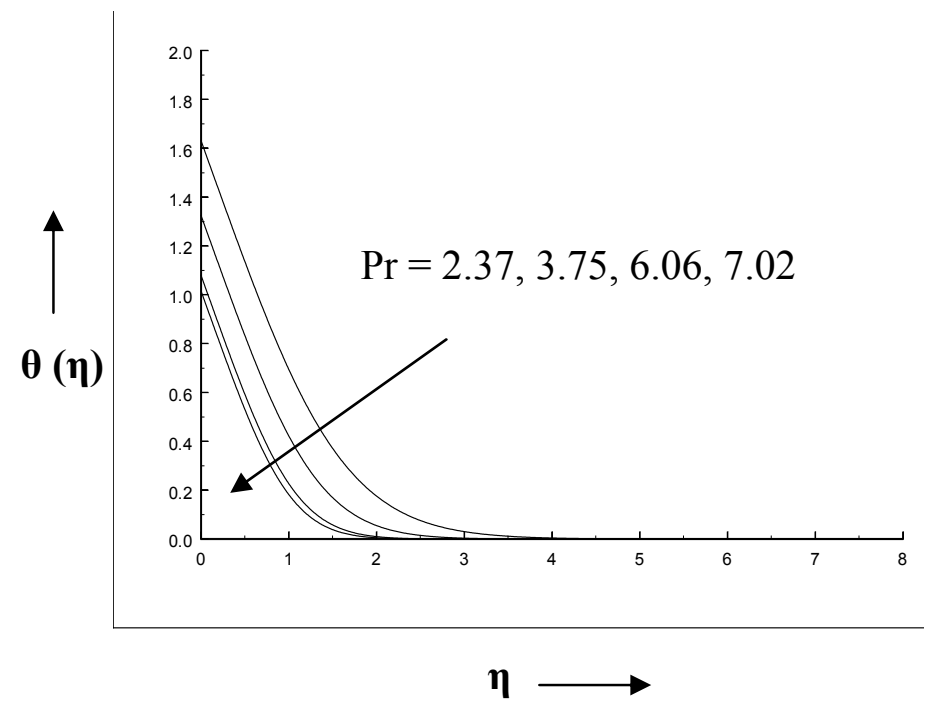

Fig. 4 Effect of Pr on temperature distribution for copper-water nanofluid 
Table 3 display the radial skin-friction coefficient $f^{\prime}(0)$, tangential skin friction coefficient $g^{\prime}(0)$ and the surface temperature $\theta(0)$ for the prescribed heat flux case (PHF case) for copper-water nanofluid. Table 3 clarifies that there is little effect on Prandtl number on the the radial skin-friction coefficient $f^{\prime}(0)$ and tangential skin friction coefficient $g^{\prime}(0)$ for copper-water nanofluid. Moreover, it is seen that with an increase in Prandtl number, there is a marked reduction in surface temperature values for the PHF case for copper-water nanofluid. These are expected, since the use of nanofluids creates a layer of hot fluid near the surface, and finally the resultant temperature of the nanofluid exceeds the surface temperature and they act as better coolants.

\section{Conclusions}

Numerical solutions are obtained to study of laminar, three dimensional, steady flow of an incompressible viscous nanofluid over a rotating disk. Copper-water nanofluid flow is analysed for the Prescribed Heat Flux (PHF case) and the effects of various nondimensional parameters are analysed. From the present study, the following conclusions are drawn.

i. The effect of Prandtl number on the radial velocity, the tangential velocity and the axial velocity for copper-water nanofluid is less significant.

ii. The effect of Prandtl number is to reduce the temperature for copper-water nanofluid for its increasing values.

iii. The effect of Prandtl number on radial skin-friction coefficient $f^{\prime}(0)$ and tangential skin friction coefficient $g^{\prime}(0)$ are insignificant for both copper-water nanofluid.

iv. Temperature at the wall decreases as Prandtl number increases for copper-water nanofluid. 


\section{References}

[1] J Herrero, J A C Humphrey and F Giralt, Comparative analysis of coupled flow and heat transfer between corotating discs in rotating and fixed cylindrical enclosures, ASME J. Heat Transfer, vol. 300, pp. 111-121, 1994.

[2] J M Owen and R H Rogers, Flow and heat transfer in rotating disc system, rotor-stator system, vol. 1, Research Studies, Taunton, UK and Wiley, New York, 1989.

[3] $\mathrm{T}$ von Karman, Über laminare and turbulente Reibung, $\mathrm{Z}$. Angew. Math. Mech., vol. 1, pp. 233-255, 1921.

[4] K Millsaps and K Pohlhausen, Heat transfer by a laminar flow from a rotating plate, J. Aeronautical Science, vol. 19, pp. 120126, 1952.

[5] S Ostrach and P R Thornton, Compressible laminar flow and heat transfer about a rotating isothermal disc, NACA Technical Note, 4320, 1958.

[6] E M Sparrow and J L Gregg, Heat transfer from a rotating disc to a fluid any Prandtl number, ASME J. Heat Tranfer C, vol. 81, pp. 249-251, 1959.

[7] M H Rogers and G N Lance, The rotationally symmetric flow of a viscous fluid in presence of infinite rotating disc, J. Fluid Mechanics, vol. 7, pp. 617-631, 1960.

[8] P D Richardson and O A Saunders, Studies of Flow and Heat Transfer Associated with a Rotating Disc, J. Mechanical Engineering Sciences, vol. 5, pp. 336-342, 1963.

[9] N Riley, The heat transfer from a rotating disc, Q. J. Mech. Appl. Math., vol. 17, pp. 331-349, 1964.

[10] R J Bodonyi, On rotationally symmetric flow above an infinite rotating disk, J. Fluid Mechanics, vol. 67, pp. 657-666, 1975. 
[11] R Kamali and A R Binesh, Numerical investigation of heat transfer enhancement using carbon nanotube-based nonNewtonian nanofluids, Int. Commun. Heat Mass Transfer, vol. 37, pp. 1153-1157, 2010.

[12] X Q Wang and A S Mujumdar, Heat transfer characteristics of nanofluids: A review, Int. J. Thermal Sciences, vol. 46, pp. 119, 2007.

[13] S U S Choi, Enhancing Thermal Conductivity of Fluids with Nanoparticles, The Proceedings of the 1995 ASME International Mechanical Engineering Congress and Exposition, San Francisco, USA, ASME, FED 231/MD, vol. 66, pp. 99-105, 1995.

[14] S K Das, S U S Choi, W Yu and T Pradeep, Nanofluids: Science and Technology, Wiley, New Jersey, 2007.

[15] E Abu-Nada and H F Oztop, Effects of inclination angle on natural convection in enclosures filled with $\mathrm{Cu}$-water nanofluid, Int. J. Heat and Fluid Flow, vol. 30, pp. 669-678, 2009.

[16] R J Tiwari and M K Das, Heat transfer augmentation in a twosided lid-driven differentially heated square cavity utilizing nanofluids, Int. J. Heat and Mass Transfer, vol. 50, pp. 2002-2018, 2007.

[17] S E B Maïga, S J Palm, C T Nguyen, G Roy and N Galanis, Heat transfer enhancement by using nanofluids in forced convection flows, Int. J. Heat and Fluid Flow, vol. 28, pp. 530-546, 2005.

[18] H E Patel, T Pradeep, T Sundarrajan, A Dasgupta, N Dasgupta and $S \mathrm{~K}$ Das, A micro-convection model for thermal conductivity of nanofluids, Pramana-J. Physics, vol. 65, pp. 863869, 2005.

[19] H C Brinkman, The viscosity of concentrated suspensions and solutions, J. Chemical Physics, vol. 20, pp. 571-581, 1952.

[20] A K Santra, S Sen and N Chakraborty, Study of heat transfer due to laminar flow of copper water nanofluid through two 
isothermally heat parallel plates, Int. J. Thermal Sciences, vol. 48, pp. 391-400, 2009.

[21] S P A Devi and R U Devi, On hydromagnetic flow due to a rotating disk with radiation effects, Nonlinear Analysis: Modelling and Control, vol. 16, pp. 17-29, 2011. 